\title{
Posverdad como repertorio de acción: disputa discursiva de la ultraderecha chilena en Facebook*
}

\author{
Post-truth as a repertoire of action: discursive dispute of the \\ chilean farright on Facebook
}

Pós-verdade como repetório de ação: disputa discursiva da ultradireita chilena no Facebook

\author{
Alonso Andrés Silva Espinoza** \\ Vicente Andrés Pizarro López***
}

\begin{abstract}
RESUMEN
El presente artículo da cuenta de cómo las comunidades de la ultraderecha nacional producen y organizan la posverdad mediante discursos políticos en Facebook. Se propone analizar las maneras en que la ultraderecha chilena utiliza la posverdad como parte de su repertorio de acción política para la producción discursiva. Para ello, se identifican estas producciones, se sistematizan los componentes internos de la posverdad allí presentes y se caracteriza cómo las comunidades ultraderechistas articulan los componentes para producir discursos políticos mediante la posverdad. En primer lugar, se revisa teóricamente el concepto a partir de su desarrollo histórico e incidencia en la comunicación y política actual, para luego incorporar las visiones tradicionales y contextualizadas, global y regionalmente, de ultraderecha. Así, mediante un enfoque cualitativo canalizado en una etnografía virtual se articula la triangulación Discurso-Cognición-Socie-
\end{abstract}

Palabras clave: comunicación digital, discursos, ultraderecha, posverdad, red social.

\footnotetext{
* El presente artículo surge del trabajo de memoria para optar al título de Sociólogo "La posverdad como repertorio de acción de la ultraderecha para la producción de discursos sociales en Facebook" (2020), tesis de pregrado para optar al grado de Licenciado en Sociología, Universidad de Valparaíso, Chile.

** Licenciado en Sociología de la Universidad de Valparaíso. Valparaíso, Chile. E-mail: alonso.silvaespinoza@gmail.com

*** Licenciado en Sociología de la Universidad de Valparaíso. Valparaíso, Chile. E-mail: vicente.apizarrolopez@gmail.com
} 
dad del análisis crítico del discurso, mostrando cómo dichas comunidades aprovechan el poco control existente en Internet mediante estrategias comunicativas subliminales y apelativas, incidiendo en la opinión pública digital y estableciendo un actuar intencional que aprovecha el potencial organizacional que brinda Facebook.

\begin{abstract}
This article shows how the communities of the national extreme right produce and organize post-truth through political speeches on Facebook. It is proposed to analyze the ways in which the Chilean extreme right uses post-truth as part of its repertoire of political action for discursive production. For this, these productions are identified, the internal components of post-truth present there are systematized and it is characterized how the ultra-right communities articulate the components to produce political discourses through post-truth. In the first place, the concept is theoretically reviewed based on its historical development and incidence in communication and current politics, to later incorporate the traditional and contextualized, globally and regionally, far-right views. Thus, through a qualitative approach channeled into a virtual ethnography, the Discourse-CognitionSociety triangulation of critical discourse analysis is articulated, showing how these communities take advantage of the little control that exists on the Internet through subliminal and appellative communication strategies, influencing digital public opinion and establishing an intentional act that takes advantage of the organizational potential that Facebook offers.
\end{abstract}

\section{RESUMO}

Este artigo entrega um relato de como as comunidades de ultradireita nacional produzem e organizam a pós-verdade através de discursos políticos no Facebook. O objetivo é analisar as formas pelas quais a ultradireita chilena utiliza a pós-verdade como parte de seu repertório de ação política para a produção discursiva. Para isso, são identificadas essas produções, sistematizados os componentes internos de pós-verdade ali presentes e se caracteriza como as comunidades de ultradireita articulam os componentes para produzir discursos políticos através da pós-verdade. Em primeiro lugar, o conceito é revisado de forma teórica a partir de seu desenvolvimento histórico e do impacto na comunicação e política atual, para então incorporar as visões tradicionais e contextualizadas, global e regionalmente, da ultradireita. Assim,
Keywords: digital communication, speeches, far-right, post-truth, social network.

Palavras-chave: comunicação digital, discursos, ultradireita, pósverdade, rede social. 
por meio de uma abordagem qualitativa canalizada em uma etnografia virtual, articula-se a triangulação Discurso-Cognição-Sociedade da análise crítica do discurso, mostrando como essas comunidades aproveitam o pouco controle existente na internet por meio de estratégias comunicativas subliminares e apelativas, influenciando a opinião pública digital e estabelecendo uma ação intencional que aproveita o potencial organizacional que o Facebook oferece. 


\section{Introducción}

La imbricación entre globalización y mundialización da cuenta de modificaciones ligadas no solo a lo económico, sino también de profundas transformaciones en la dimensión cultural y social, comprendiéndose entonces como procesos por sí mismos y, a la vez, inscritos en un circuito de desarrollo simultáneo (Berardi, 2007; Boltanski y Chiapello, 2003). Así, la metamorfosis que subyace al desarrollo tecnológico del ámbito productivo en el capitalismo se materializa a su vez en cambios en las relaciones sociales y en la identidad de los sujetos dentro de la sociedad (Berardi, 2007). Por tanto, una de las características del capitalismo contemporáneo son las relativamente nuevas formas de relaciones sociales e identidades que genera el circuito globalizaciónmundialización y que permiten identificar y cuestionar los consensos que interiorizan las sociedades en pos de la convivencia (Beasley-Murray, 2010; Berardi, 2007; Boltanski y Chiapello, 2003). Es aquí donde entra en juego la importancia de la introducción de Internet a dicho circuito, implicando cambios elementales dentro de la estructura social y constituyendo, a su vez, un lugar de cultura digital donde se articulan identidades, subjetividades y simultaneidad de subculturas (Castells, 2014; Hine, 2004; Lasén y Puente, 2016).

Lo anterior permite esclarecer el cambio de paradigma que ha significado Internet, interiorizando su uso en ámbitos de la vida cotidiana para transformar las relaciones sociales de manera permanente (Hine, 2004; Lasén y Puente, 2016; Simondon, 2007). Así, Internet se concibe como un espacio de visibilidad y enunciación con una vasta posibilidad de producir significados y discursos, en tanto se comprende como dispositivo de saber y poder (Deleuze, 1990; Foucault, 2002), constituyente de prácticas sociales propias del ciberespacio. Por consiguiente, Internet se alza como un espacio de disputa ideológica y poder que, por medio de la capacidad de los discursos de estructurar las comunidades virtuales, produce saberes y significados que dan coherencia interna a las relaciones sociales en cuestión (Hine, 2004; Foucault, 2005; Ponce-Tarré 2018; Rojas, 2017; Van Dijk, 2003).

En este contexto, el concepto de posverdad se comprende dentro del fenómeno de la información no verídica y malintencionada, que busca influir en espacios de disputa discursiva e ideológica (Álvarez, 2018; Hernández, 2017; Llorente, 2017; Ponce-Tarré, 2018; Rojas, 2017). 
Así, en tiempos de hiperconectividad y altos flujos de información, se posibilita el surgimiento y propagación de fake news ${ }^{4}$, un tipo de posverdad comprendida como noticias aparentes, pero de contenido engañoso, que circulan en Internet y desinforman a los usuarios de manera deliberada (Calvo y Aruguete, 2020; Pina, 2017). Simultáneamente, el fenómeno encuentra un hábitat en las relaciones sociales marcadas por la sociedad del espectáculo y cómo las representaciones de lo experimentado han desplazado la experiencia misma de lo vivido (Debord, 1967), con lo cual Internet se consolida como el espacio de relaciones por medio de dibujos, apariencias y representaciones mentales por antonomasia.

En consideración con lo anterior, la existencia de sucesos internacionales como el Brexit, la presidencia de Donald Trump o la de Jair Bolsonaro, permiten establecer una conexión entre la utilización de la posverdad como un recurso político y la ultraderecha actual, aunque no de manera exclusiva con dicho sector político (Álvarez, 2018; Llorente, 2017; Ponce-Tarré, 2018; Rojas, 2017). Paralelamente, surgen nuevas articulaciones de la extrema derecha que nacen desde la organización web, rememorando a la Alt-Right que se dio a conocer en Estados Unidos y que buscan disputar los discursos políticos y sociales en la opinión pública digital (Calvo y Aruguete, 2020; Reguera, 2017; Rojas, 2017). En lo que respecta al caso nacional las manifestaciones -y tomando como ejemplo la revuelta popular en Chile vivida desde octubre del 2019 y que se entiende como categoría emergente de análisis - han estado cargadas de una disputa cultural y han tenido respuesta directa en los sectores más conservadores. Este tipo de acción de contestación se volvió notoria a partir del levantamiento popular, materializándose en lo digital especialmente en lo que respecta a las campañas en torno al plebiscito por una nueva constitución. Esta idea de una ultraderecha - que aprovecha la plataforma digital para articular la posverdad como respuesta durante el estallido social- supone también disputar una hegemonía sobre la base de códigos que

4 Si bien el concepto de fake news se vincula de gran manera con la posverdad, no significan necesariamente lo mismo. La lógica detrás de estos conceptos es que toda noticia falsa es posverdad, pero no toda la posverdad es una noticia falsa, debido a que el concepto de posverdad engloba una noción más amplia y no necesariamente exclusiva de los hechos noticiosos. 
los sectores de izquierda han establecido tanto en las calles como en el ágora virtual. Ejemplo de esto es la disputa (tanto en nombre como en materialidad) por la ahora llamada Plaza de la Dignidad, la figura del perro Negro Matapacos o el significado político tras la canción de Víctor Jara El derecho de vivir en paz, visibilizando la inmediatez con que la posverdad es utilizada como recurso político en una coyuntura socialmente disputada.

En consideración con lo anterior y basándose en el concepto de acción colectiva (Tilly, 1978), en tanto amalgama de acciones deliberadas que son destinadas a concretar los objetivos de algún movimiento o agrupación social, se concibe la posverdad dentro del repertorio de acción política de la ultraderecha contemporánea, con lo que se pretende incidir en el debate que se produce en el ágora digital. Por ello, esta investigación buscó dar respuesta a la pregunta de investigación: ¿De qué manera la ultraderecha chilena utiliza la posverdad como parte de su repertorio de acción política para producir discursos en Facebook?

En función de lo anterior los objetivos de la investigación fueron:

- Identificar cuáles eran los discursos políticos producidos por la ultraderecha chilena a través de la posverdad.

- Sistematizar los componentes internos de la posverdad utilizada por la ultraderecha chilena para la producción de discursos políticos.

- Caracterizar cómo las organizaciones políticas y medios de comunicación independientes de ultraderecha articulaban dichos componentes internos para producir discursos políticos por medio de la posverdad.

\section{Estado de la discusión}

\subsection{Líneas investigativas}

Resulta importante aclarar desde un principio que la posverdad constituye un neologismo en el contexto digital, lo que se refleja en las investigaciones que la estudian y que destacan su carácter novedoso e implicancias en la discusión teórica. Se le adjudica la acuñación académica a Tesich (1992), quien aludía a una banalización de la verdad 
en casos noticiosos a la hora de forjar la opinión pública, lo que impacta directamente en las prácticas de formación y socialización de la ciudadanía. Hoy, el término adquiere un cariz fuertemente vinculado con las nociones de verdad y mentira en el contexto de la comunicación digital. No obstante, las ideas que subyacen al concepto no son realmente nuevas, ya que a grandes rasgos la posverdad se comprende como el conjunto de aquellas situaciones donde las subjetividades priman por sobre los hechos y su concordancia con la realidad, aunque guarda una importante diferencia con la mera mentira política (Álvarez, 2018; Berckemeyer, 2017; Chillón, 2017; Fowks, 2017; Hernández, 2017; Llorente, 2017; Ponce-Tarré, 2018; Rojas, 2017; Zarzalejos, 2017). En 2004, Keyes (2011) popularizó el término al poner énfasis en su función de manipulación creativa de la verdad, para propiciar una postura social o política determinada (Hernández, 2017).

Este desarrollo académico del concepto identifica una tendencia en el estudio de la posverdad desde una lógica de denuncia respecto de cuáles son las interacciones reales que subyacen a los procesos de socialización, y formación ideológica en la época del auge de la comunicación digital y su implicancia en las prácticas cotidianas. Así, son los procesos contingentes recientes y el auge de las redes sociales digitales los que han motivado el incremento de estudios relacionado con la posverdad. En este sentido, la discusión teórica contemporánea parece encontrar sus grandes debates en torno a dimensiones como la posverdad y su relación con la política, el lenguaje, la cultura, la educación, la economía y los medios de comunicación.

Entre las principales líneas investigativas en torno al tema es posible encontrar aquellas enfocadas en el estudio de las fake news y que rememoran fuertemente los estudios culturales, en particular latinoamericanos a partir de la década de los ochenta con su enfoque de cultura-poder respecto de los medios de comunicación, tecnología y la creación de nuevas prácticas sociales (Fernández, 2011). En este caso, el énfasis está puesto tanto en el concepto de las noticias falsas por sí solo, como en sus repercusiones globales en una sociedad altamente interconectada (Álvarez, 2018; Amorós, 2018; Corbillón, 2018; Fernández-García, 2017; Pina, 2017; Quirós, 2017).

Otra gran corriente investigativa profundiza en la posverdad, fake news, y su impacto directo en los medios de comunicación, centrán- 
dose en las transformaciones sustanciales de los medios de comunicación, la rentabilidad de la prensa, la sociedad del espectáculo, los nuevos medios de comunicación alternativos, el rol de la audiencia como ente participante en los procesos comunicacionales y la naturaleza de la información que circula (Álvarez, 2018; Hernández, 2017; Llorente, 2017; Mazzone, 2018; Ponce-Tarré, 2018). Igualmente, existen también aquellas investigaciones que ahondan en la imbricación posverdad, fake news y política y que abarcan el vínculo existente de las problemáticas internacionales, la opinión pública y producción discursiva e ideológica, entre otros aspectos. Estos trabajos permiten comprender la posverdad como mecanismo que favorece intereses y pensamientos políticos a través de prácticas discursivas y la operacionalización de emociones y sentimientos como herramienta en la esfera política, ahondando particularmente en el posicionamiento sociopolítico de la opinión pública (Álvarez, 2018; Calvo y Aruguete, 2020; Corbillón, 2018; Ponce-Tarré, 2018; Rojas, 2017).

Por su parte, las investigaciones que vinculan la posverdad, fake news, y redes sociales permiten comprender el panorama respecto de la posverdad y la tecnología digital web, las redes y las relaciones sociales online, entre otros aspectos (Álvarez, 2018; Llorente, 2017), con lo cual no solo se cuestiona la información mediada en la web, sino también se disputa la noción misma de verdad en tiempos digitales, así como la producción y reproducción de la información en línea, donde las redes sociales se sitúan como el nuevo campo de disputa ideológica al convertirse en las herramientas desinformativas por excelencia debido a la falta de control sobre ellas (Calvo y Aruguete, 2020; Hernández, 2017; Llorente, 2017; Mazzone, 2018; Ponce-Tarré, 2018; Rojas, 2017; Zarzalejos, 2017).

Por su parte, en lo que respecta a investigaciones acerca de ultraderecha, estas ofrecen una orientación general respecto de cuál es su escenario político y de sus recientes condiciones de ascenso (Orjuela, Chagas-Bastos y Chenou, 2017). Aquí los esfuerzos académicos se enfocan tanto en la faceta institucionalista (apegada a las normas del juego político en tanto legitimación sociopolítica) y populista de esta facción, como también en el rol que desempeñan las nuevas tecnologías de la comunicación y redes sociales como validación y articulación de la ultraderecha a escala global, siendo la Alt-Right un notorio 
tópico de estudio (Barolin, 2017; Gómez, 2017; Nagle, 2017; Reguera, 2017; Tiempo Devorado, 2017).

El aporte que busca dar este artículo se sustenta en que se trata de una discusión teórica que se está desarrollando actualmente. El equipo investigador cree fundamental comprender parte de la orgánica de Internet, las redes sociales y la absorción instantánea de información que produce la comunicación digital como espacio de representación de la realidad social, configurándose como campo de disputa política, lo que queda demostrado en trabajos como el de Zeyu (2019), Calvo y Aruguete (2020), Fuchs y Schäfer (2020), Van Erkel y Van Aelst (2020), Wang, Nguyen, Dai, Chi y Dow (2020) por nombrar algunos. Dado este contexto, resulta fundamental ahondar en el auge de la extrema derecha, puesto que el apoyo social que han recibido sus organizaciones, movimientos y medios informales de comunicación recientemente no puede ser analizado fuera de su condición digital ni de las tecnologías de la comunicación actual, concediéndole además el merecido peso a los nuevos proceso ciberdemocráticos.

\subsection{Articulación teórica}

La definición ocupada por Oxford al catalogar la posverdad como palabra del año en 2016 fue: "Relating to or denoting circumstances in which objective facts are less influential in shaping public opinion than appeals to emotion and personal belief ${ }^{\prime 5}$ (Oxford English Dictionary, 2016). Se toma esta definición como punto inicial puesto que gran parte de la literatura consultada incorpora o se aproxima bastante a esta, por lo cual se puede establecer un consenso en cuanto al significado de la posverdad (Álvarez, 2018; Berckemeyer, 2017; Chillón, 2017; Fowks, 2017; Hernández, 2017; Llorente, 2017; Ponce-Tarré, 2018; Rojas, 2017; Zarzalejos, 2017). Además, se parte de la base de que la opinión pública se comprende como el espacio de legitimación de la verdad socialmente aceptada y, por ende, es un espacio de disputa constante (De Angelis, 2017).

5 La definición puede traducirse como "aquello que se relaciona con situaciones en donde los hechos objetivos pesan menos que las emociones y las creencias personales al momento de moldear la opinión pública" (traducción propia). 
Ahora bien, posverdad no es un mero sinónimo de mentira. Tesich (1992) ya lo adelantó al aludir a la pérdida de importancia de la verdad, al ser relativizada y convertida en algo de segunda importancia a la hora de generar un juicio valórico, suponiendo un cuestionamiento a la forma de interpretar la información existente en la web y, por extensión, al usuario como ser cultural y agente crítico capaz de incorporar el análisis de lo explícito y lo implícito (Berckemeyer, 2017; Hernández, 2017; Llorente, 2017; Ponce-Tarré, 2018). Además, es menester comprender que el nuevo desarrollo de las relaciones digitales se caracteriza por una inhibición en el impacto que causa el engaño en un contexto online (Álvarez, 2018; Keyes, 2011). De esta forma, resultaría imprudente desligar la posverdad del mundo digital, pues este es idóneo para la producción de posverdad y fake news (Hernández, 2017; Mazzone, 2018; Ponce-Tarré, 2018). En este contexto, las redes sociales digitales han transformado la cultura de masas (Horkheimer y Adorno, 1998) a través de contenidos personalizados que, al verse sin mucho control de lo publicado en Internet, ofrecen la oportunidad de desinformar y alienar a gran escala, en tanto que altera la percepción de los usuarios incluso de maneras contradictorias (Calvo y Aruguete, 2020; Mazzone, 2018; Prego, 2017; Rojas, 2017). De esta forma, la posverdad es utilizada frecuentemente como recurso estratégico que pasa por alto la rigurosidad ética comunicacional y política (Rojas, 2017), de modo que la manera en que se emplea la posverdad estará en función de alcanzar ciertos objetivos donde la apelación emocional se superponga a lo que se condice con los hechos y la realidad, es decir, con lo verdadero (Ponce-Tarré, 2018). Esto vislumbra una piedra angular en la noción de posverdad, ya que la importancia no radica en convencer que lo falso es verdadero, sino que la dicotomía misma verdadero-falso carece de importancia a la hora de generar un juicio de valor y es opacada completamente por las subjetividades que despierta la posverdad. En otras palabras: que algo sea verdadero o falso no tendría peso en la formulación de la opinión pública.

La dimensión de la posverdad como un recurso estratégico afín a la política es, entonces, causal, apelativa y alienadora. Desde un marco discursivo (Foucault, 2005), la posverdad convierte las creencias personales en algo irrefutable e imbatible, posicionándose por encima de la lógica y la objetividad de los hechos (Llorente, 2017; Zarzalejos, 2017). Por su parte, la posverdad es política en la medida en que aborda lo 
político, en tanto identidad antagónica propia de la vida en comunidad que permea la orgánica de las relaciones sociales (Mouffe, 1999), de ahí que esta pueda entenderse en función de favorecer a sectores políticos, económicos, o de otro tipo, mediante la manipulación del mensaje con tal de influir directamente en la opinión pública (Calvo y Aruguete, 2020; Rojas, 2017).

Por su parte, hablar de ultraderecha contemporánea resulta un ejercicio complejo, puesto que el término no posee un perfil homogéneo y, en muchos casos, no se logra consenso (González, 2016; Rodríguez, 2003). La cuestión del origen, por ejemplo, parece ser difusa, ya que se hace mención a la crisis económica, la globalización cultural, la inmigración, mientras otros hablan de una renovación, resurgimiento e incluso de una ultraderecha completamente distinta (Barolin, 2017; Gómez, 2017; Reguera, 2017; Sanahuja, 2019). En principio, la idea de una derecha tradicional comprende, grosso modo, un grupo político conservador defensor de la dominación que ejercen los sistemas como el capitalismo y el patriarcado, basándose en el consenso de un orden y jerarquía social rígida y natural, con un cierto grado de tolerancia hacia el multiculturalismo valórico, mientras que por otro lado, la ultraderecha lleva dicha postura a una ideología política conservadora más radical que alcanza puntos considerados antidemocráticos (Arendt, 1998; Rodríguez, 2003). Complementariamente, es posible comprender la ultraderecha no solo por lo que es, sino también por lo que no es. Así, resulta funcional establecer que este sector político se opone al progresismo, al colectivismo, laicismo, reformismo social, multiculturalidad étnica, etc. De esta forma, por definición la ultraderecha concibe entre sus componentes la exclusión identitaria, xenofobia, etnonacionalismo extremo, retórica populista, tradicionalismo, conservadurismo, autoritarismo y populismo, entre otras (González, 2016; Mudde, 2007). Todo lo anterior implica que los discursos de la extrema derecha no son la expresión inmediata y arrebatada de algún irracionalismo político, sino que encierra un marco de coacción lógica que da sentido causal a su ideología (Arendt, 1998; González, 2016).

Dentro de ese marco figura un derrotismo político y social que busca reivindicarse a través de figuras carismáticas (Orjuela et al., 2017). De esta forma, es posible identificar en la narrativa ultraderechista una pertenencia a grupos de desposeídos y olvidados por parte 
del gobierno (progresista) y de los triunfadores que les arrebataron todo (Yehiya, 2017). Por ello, dicho sector político recurre al legado de la tradición como autoridad moral y social, a la nostalgia del pasado, de la identidad y pertenencia a una comunidad (Arendt, 1998; Gómez, 2017). Por lo mismo, las prácticas discursivas de la ultraderecha incorporan la filosofía de la crisis permanente e inminente, donde el momento de actuar es el ahora, en función del miedo de una supuesta inestabilidad del orden sociopolítico y así depositar la confianza en figuras populistas que se atribuyen la capacidad de resolver las problemáticas en cuestión (Gómez, 2017; Orjuela et al., 2017). Se yergue, entonces, como antipluralista al alegar un monopolio en la representación de los reales intereses del pueblo en cuestión. En adición, la identidad y su conservación forja gran parte del entramado ideológico de la extrema derecha, puesto que permite identificar un exogrupo a quien culpar y un endogrupo, que siente que su mundo se desmorona (Gómez, 2017).

Ahora bien, la noción de ultraderecha debe comprenderse desde las particularidades de su propia historicidad. Es por ello que resulta imprudente estudiarla sin incorporar el auge de las nuevas tecnologías de comunicación y de las redes sociales, ya que es allí donde los grupos políticos - la ultraderecha en este caso-, buscan organizarse en la era digital, (Rodríguez y Sánchez, 2013), es decir, se comprende la extrema derecha articulada en las plataformas digitales (Gómez, 2017; Reguera, 2017). En este sentido, movimientos como la Alt-Right en Estados Unidos han demostrado la viabilidad de las redes sociales para forjar organizaciones políticas activas, permitiéndoles encontrar un respaldo ideológico a tan solo un clic de distancia y alejada de la imagen del skinhead o neonazi tradicional, así como también incorporar a intelectuales trajeados y celebridades carismáticas capaces de presentar discursos estructurados con ideas provocativas, sobre la base de talentos comunicativos y sofisticación intelectual (Calvo y Aruguete, 2020; Nagle, 2017, Reguera, 2017; Rodríguez y Sánchez, 2013; Yehya, 2017).

Finalmente, en lo que respecta a la conceptualización de ideología el punto de partida corresponde a la noción de Marx y Engels (1974), que la comprenden como un conjunto de creencias compartidas además de representaciones de la realidad a partir de las con- 
diciones materiales de la sociedad y, a su vez, deformada por la falsa conciencia de lo que es la realidad. Al encontrarse en una relación directamente proporcional con la realidad material, será la clase dominante la que determinará el conjunto de representaciones de la realidad, monopolizando los medios de producción materiales e ideológicos y legitimando su posición a través del control de la producción de ideas (Marx y Engels, 1974). A su vez, de Althusser (1974) se rescata la ideología como representación de la relación imaginaria y simbólica de los individuos con sus condiciones reales de existencia, actuando como legitimación que da sentido a la realidad material que opera directamente en la psique de los sujetos. De forma complementaria se aborda el enfoque gramsciano y el uso de los aparatos ideológicos del Estado en función de mantener un consenso respecto de la justificación de la hegemonía, en tanto subyugación económica y sociocultural (Gruppi, 1978). La ideología dominante, legitima el orden social de la realidad determinada por las relaciones de producción, lo cual permite comprender el proyecto hegemónico como la compenetración cultural del capitalismo de manera totalizadora (Althusser, 1974; Gruppi 1978).

Paralelamente y desde lo desarrollado por Zizek (2003), quien se nutre desde el idealismo hegeliano y psicoanálisis de Lacan, se comprende que tanto el sujeto como la realidad son ideológicas, siendo la relación sujeto-realidad siempre directa, simultánea e ideológica. Así, la ideología no es algo externo al sujeto o a la realidad, sino que forma parte de su constitución y apela a este en cada instancia de su vida. Por ello, respecto de la producción ideológica y política de discursos, la ideología organiza las actitudes de los grupos sociales que consisten en opiniones generales organizadas esquemáticamente acerca de temas sociales relevantes (Van Dijk, 2003), determinando normas y valores sociales que se integrarán como componentes que organizan la ideología del grupo. Esta capacidad de influir en las creencias de los sujetos genera cogniciones personales representadas en modelos mentales que influyen en procesos de socialización y comunicación (Van Dijk, 2003). Así, es posible entender que las ideologías no son necesariamente negativas o falsas, ya que no solo los grupos dominantes determinan la ideología para legitimar el poder y construir y disputar la hegemonía sociocultural (Gruppi, 1978; Van Dijk, 2003). En este sentido, los discursos cobran relevancia al ser tratados desde la ideología, 
ya que se entiende que esta se encuentra adscrita al discurso, debido a que estos se producen y reproducen desde una posición y con una intención práctica, influyendo en la vida social (Eagleton, 1997).

Finalmente, la triada Posverdad-Discurso-Ideología se esclarece al pensar la ideología como un proceso de dominación, legitimidad y promoción de los intereses de los grupos que disputan el poder, en este caso particular, la derecha más radical (Eagleton, 1997; Van Dijk, 2003). Así, en las redes sociales no se disputan discursos políticos solamente, sino que un posicionamiento ideológico puede ser instrumentalizado por medio de ellas.

\section{Metodología}

\subsection{Pregunta de investigación y objetivos}

Como se adelantó, la pregunta de investigación que este artículo buscó responder es: ¿De qué manera la ultraderecha chilena utiliza la posverdad como parte de su repertorio de acción política para producir discursos en Facebook?

Por su parte, los objetivos diseñados para dar respuesta a dicha interrogante fueron los siguientes:

- Analizar las maneras en las que la ultraderecha chilena utiliza la posverdad como parte de su repertorio de acción política para la producción de discursos políticos en Facebook.

- Identificar cuáles son los discursos políticos producidos por la ultraderecha chilena a través de la posverdad.

- Sistematizar los componentes internos de la posverdad utilizada por la ultraderecha chilena para la producción de discursos políticos.

- Caracterizar cómo las organizaciones políticas y medios de comunicación independientes de ultraderecha articulan dichos componentes internos para producir discursos políticos por medio de la posverdad.

\subsection{Enfoque metodológico}

El presente artículo incorporó un enfoque metodológico cualitativo, ya que ello brinda la posibilidad de un análisis e interpretación de sig- 
nificaciones, posicionamientos y discursos políticos existentes en la red social (Canales, 2006). A su vez, se planteó seguir una línea etnográfica debido a su capacidad de dar cuenta de cómo las tradiciones, roles, valores y normas de un ambiente se internalizan, lo cual genera regularidades que pueden explicar la conducta individual y grupal en forma adecuada, al mismo tiempo que develar el comportamiento virtual de las páginas ultraderechistas en Facebook (Murillo y Martínez, 2010).

Ahora bien, considerando la naturaleza digital a la que se adscribe este trabajo, la aplicación de una etnografía virtual fue crucial al permitir alcanzar un sentido enriquecido de los significados que adquiere la tecnología en las culturas que la alojan o que se conforman gracias a ella (Hine, 2004). Así, comprendiendo Internet como espacio de socialización digital donde se gesta una cultura y también como artefacto cultural generado por personas, con objetivos y prioridades, el enfoque etnográfico virtual da pie para comprender Internet como cultura y como espacio de reproducción de prácticas culturales en que se construyen subjetividades y discursos, situados en un contexto sociohistórico que refleja una determinada cultura en ellas (Hine, 2004).

\subsection{Muestra y recolección de datos}

Producto de la alta cantidad de grupos y páginas de derecha en Facebook - la red social con mayor compenetración y nivel de interacción con más de dos mil millones de usuarios (Internet World Stats, 2020) y la incapacidad del presente estudio de abarcarlas todas, se efectuó un muestreo por conveniencia, para lo cual se definieron criterios de selección para las comunidades virtuales.

El primer criterio para la conformación de la muestra fue que se tratara de páginas de organizaciones, movimientos o medios informales de comunicación de derecha. Esto se aseguró por medio de la revisión de perfiles, publicaciones, comentarios, manifiestos y su contenido exhibido o compartido en la plataforma, lo que permitió perfilar y caracterizarlas como grupos pertenecientes a la derecha según lo abordado en el apartado teórico. Por otro lado, se contempló que las comunidades debían contar con una cantidad mínima de 10.000 seguidores y con una participación activa en la plataforma, es decir, que generaran contenido de manera constante para así asegurar representatividad y alcance en la web. 
Además de lo anterior, las publicaciones seleccionadas - la unidad muestral de estudio- debían pertenecer a la categoría de fake news y posverdad en tanto presentaban: sátira, parodia de noticias, noticias fabricadas, fotos manipuladas o apelación directa al sentir de la audiencia. El mismo muestreo por conveniencia facilitó la tarea de selección de publicaciones, la que se realizó mediante observación no participante y a través de la herramienta de búsqueda de Facebook. De este modo fue posible elegir aquellas que contaban con un nivel considerable de reacciones, comentarios y muchas veces en las que fueron compartidas, para alimentar el algoritmo de Facebook y así magnificar su alcance inicial al considerarlas como publicaciones "interesantes", con lo cual se ampliaba su alcance y representatividad en el feed de Facebook (Birkbak y Carlsen, 2016). Así, las publicaciones abarcaron desde las 400 interacciones, 100 comentarios y 130 veces compartidas, hasta más de 4.000 interacciones, 3.000 comentarios y 17.000 veces compartidas.

Por otro lado, el corpus de comunidades virtuales con las que se trabajó consta de dos organizaciones políticas y dos medios informales de comunicación de ultraderecha, con un punto de saturación - definido por los propios autores una vez recolectadas las unidades muestrales y luego de identificar ciertos patrones comunes en los que se ahondará en el apartado de resultados- de ocho publicaciones con posverdad. Ello permitió comprender las pautas estructurales y orgánicas de funcionamiento que definen al objeto de estudio, así como también representar y comprender la naturaleza de las relaciones que lo configuran socialmente (Mejía, 2014). Es importante aclarar que este punto de saturación evitó incorporar la repetición innecesaria del conocimiento al recolectar unidades muestrales ya trabajadas, esquivando así una posible redundancia de casos. De esta forma, se abordaron dos publicaciones por comunidad:

a) Ciudadanos Por Un Chile Mejor. Medio informal de comunicación que cuenta con 278 mil seguidores ${ }^{6}$. Opera políticamente como medio comunicacional ciudadano (publica noticias o sucesos coyunturales) y se sitúa como un nuevo referente político contra el

$6 \quad \mathrm{Al}$ igual que en el resto de seguidores de las otras comunidades, estos datos corresponden al momento de captación. 
populismo, marxismo, corrupción y la izquierda (Ciudadanos Por Un Chile Mejor, s.f.).

b) Corrupción Chile. Medio informal de comunicación autodefinido como medio libre e independiente. No obstante, de manera constante y abierta, entrega apoyo a organizaciones de ultraderecha como el Partido Libertario a través de propaganda política, invita a seguir su contenido y a formar parte de sus instancias de debate, además de explicitar su posicionamiento político de derecha en aspectos relativos a la migración, seguridad, política y economía (Corrupción Chile, s.f.). Cuenta con 263 mil seguidores.

c) Acción Identitaria. Movimiento social identitario que se autopresenta como respuesta al progresivo y deliberado olvido de la identidad nacional, deteriorada ante la globalización y los antivalores del mundo moderno. Prioriza la importancia de la tradición y la patria por sobre la población inmigrante y el efecto negativo que esta tiene en el país (Acción Identitaria, 2016). Con 37 mil seguidores, se posiciona abiertamente en contra del multiculturalismo, la inmigración y las disidencias sexuales, en pos del nacionalismo y tradicionalismo e interviene tanto en el espacio digital como en el espacio público.

d) Partido Social Patriota. Organización política ultranacionalista, conservadora y tradicionalista en contra del globalismo. Busca detener la inmigración desatada, la desintegración de la persona y familia, el terrorismo étnico y la fragmentación nacional, puesto que implica la destrucción de la identidad nacional (Juventud Social Patriota, 2019). Cuenta con 12.000 seguidores.

\subsection{Instrumento, producción y técnica de análisis de datos}

La producción de datos utilizó una matriz de análisis diseñada por Rivera (2018), sobre la base del análisis crítico del discurso de Van Dijk (2016) - ahora en adelante ACD - con modificaciones que permiten aplicarla al objeto de estudio. Esto posibilitó operacionalizar las publicaciones, desmenuzándolas en función de un análisis minucioso de cada componente que daba forma al discurso. El instrumento, que busca dar cuenta de las macroestructuras semánticas, los esquemas discursivos, el significado local, el estilo, los recursos retóricos, el ni- 
vel contextual, la dimensión interaccional, el nivel de viralización, los comentarios relevantes y el método de verificación, se encuentra disponible en el anexo.

De igual manera, la técnica de análisis corresponde al ACD. La triangulación Discurso-Cognición-Sociedad en el ACD remite tanto al acontecimiento comunicativo, como a las estructuras, representaciones o procesos mentales, y las micro-macroestructuras de interacción social, permitiendo acceder a lo explícito e implícito del discurso (Van Dijk, 2016). Lo anterior da cuenta de la relación entre las estructuras sociales y los discursos presentes, para comprender la sinergia entre sus componentes, analizar e interpretar las publicaciones con posverdad e identificar y caracterizar las estrategias discursivas que evidencian la reproducción del poder político en la plataforma web.

\subsection{Consideraciones éticas en el contexto digital}

Debido a la naturaleza digital de esta investigación resulta apropiado clarificar las consideraciones éticas y evitar perjuicio alguno a las personas involucradas, por lo que se resguardaron y protegieron todas las identidades e información sensible de quienes habían participado de manera directa o indirecta en la publicación. No obstante, no se ocultó ni protegió información asociada a figuras públicas, y solo se mostraron los nombres de las organizaciones y medios de comunicación estudiados. A su vez, este artículo se guía y adhiere a los principios fundamentales para un acercamiento ético de la Asociación de Investigadores de Internet, en tanto estos permiten un correcto actuar investigativo de lo digital (Markham y Buchman, 2012).

\section{Resultados}

\subsection{Naturaleza y distribución de los discursos identificados}

Tras la aplicación de la matriz se identificó la naturaleza y contenido de los discursos en las publicaciones. Respecto a las organizaciones políticas, los discursos se refieren a temáticas relacionadas con el feminismo, los movimientos sociales, la migración, los derechos humanos, el nacionalismo y el globalismo. Por su parte, los discursos de medios informales de comunicación se vinculan con la política institucional e internacional, la economía, la censura, la corrupción, las figuras pú- 
blicas, el comunismo, el pueblo mapuche, los movimientos sociales y los derechos humanos. No obstante estos discursos no son excluyentes entre sí, presentándose simultáneamente en las publicaciones. Los discursos se distribuyen de la siguiente manera:

\section{Organizaciones políticas}

a) Acción Identitaria: Movimientos sociales, feminismo, migración, política internacional.

b) Partido Social Patriota: Nacionalismo, globalismo, proyectos políticos, política institucional, derechos humanos, migración, globalización, política nacional.

\section{Medios informales de comunicación}

a) Corrupción Chile: Política institucional, economía, figuras públicas, pueblo mapuche, movimientos sociales, derechos humanos.

b) Acción Identitaria: Censura, corrupción, política institucional, figuras públicas, moral y ética, $\mathrm{FPMR}^{7}$, política nacional.

Este tipo de contenido, al estar en la palestra, permite a la ultraderecha precisamente disputar la narrativa respecto del orden social en la plataforma digital. Esto es que por medio de Facebook el accionar político colectivo incrementa su alcance organizacional, intensificando la capacidad de ejercer una resistencia política en torno a los discursos que se disputan en la coyuntura nacional (Tilly, 1978). Así, no solo se instaura a Facebook como un ágora digital, sino que también se establece que los mismos grupos de ultraderecha lo comprenden así y lo interiorizan como un espacio beneficioso para alcanzar sus objetivos colectivos (Calvo y Aruguete, 2020; Ponce-Tarré, 2018; Rojas, 2017; Rodríguez y Sánchez, 2013; Tilly, 1978).

7 Frente Patriótico Manuel Rodriguez, fue una organización guerrillera chilena que tenía dentro de sus propósitos ejercer una resistencia política y armada para derrocar al dictador Augusto Pinochet. 


\subsection{El formato fake news}

La Tabla 1 sintetiza los principales aspectos relacionados con este aspecto.

Tabla 1

Sintesis de resultados del formato de fake news

\begin{tabular}{ll}
\hline Dimensión de análisis & Síntesis \\
\hline & Los grupos catalogados como medios \\
& informales de comunicación concentran la \\
& totalidad de publicaciones con formato fake \\
Formato fake news & en la legitimidad que producen los medios de \\
& comunicación y el formato de noticia. \\
\hline
\end{tabular}

Fuente: Elaboración propia.

En estrecha relación con lo anterior, es posible hacer una identificación de las publicaciones que presentan hechos noticiosos bajo un formato de fake news. Su importancia recae en que son justamente los grupos caracterizados como medios informales de comunicación los que concentran todas las publicaciones con dicho formato, tras aparentar una cierta formalidad que enmascara la desinformación deliberada (Pina, 2017). Así, aquella estructura cuasi-noticiosa inspira un grado de credibilidad, ya que prima el cómo se cuenta un suceso por sobre aquello que se está informando (Illades, 2018). El proyecto hegemónico de la ultraderecha hace uso de esta fórmula en la publicación para aprovechar la ilusión ideológica de ese sentimiento de legitimidad que producen los medios de comunicación a un nivel cultural (Gruppi, 1978). Al respecto, las publicaciones de por sí no cuentan con fuentes que permitan corroborar ni contrastar su contenido. No obstante la matriz de análisis permite realizar este paso gracias a su nivel de fact-checking: una publicación que informa acerca de un supuesto infiltrado del FPMR en el Instituto Nacional sirve de ejemplo a este propósito (Ciudadanos Por Un Chile Mejor, 2019).

En este caso, el recurso verificador fue el perfil de Twitter, que resultó en una cuenta falsa de parodia (Almeyda, s.f.). Tras revisar las publicaciones, se identificó que el perfil hostiga constantemente a personas de izquierda, publica noticias falsas, y desde la ironía y "humor" ataca a otros perfiles de la plataforma. Además, la supuesta foto de René Al- 
meyda corresponde a una plantilla de una biblioteca de fotos de libre acceso en Internet.

\subsection{El sentido de la retórica ultraderechista en los discursos}

En la Tabla 2 se despliegan los resultados respecto de este aspecto.

Tabla 2

Síntesis de resultados de la retórica ultraderechista presente en los discursos analizados

\begin{tabular}{ll}
\hline Dimensión de análisis & Síntesis \\
\hline $\begin{array}{l}\text { El sentido de la retórica } \\
\text { ultraderechista en los }\end{array}$ & $\begin{array}{l}\text { Identificación del enemigo interno o externo } \\
\text { en una narrativa que busca comunicar las } \\
\text { especificidades y códigos políticos propios de } \\
\text { la ultraderecha. }\end{array}$ \\
\hline
\end{tabular}

Fuente: Elaboración propia.

Según las comunidades virtuales de ultraderecha, es posible dar cuenta de que cada una de ellas identifica a uno o más enemigos, internos o externos, asociándoles características negativas en la narrativa de sus publicaciones. Así, buscan no solo posicionar a un otro como un adversario, sino también construir un discurso sobre la base de la deslegitimación de ese otro, bajo el prisma de la exclusión identitaria, tradicionalismo, autoritarismo, el conservadurismo y la retórica populista, con lo cual persiguen mantener o restaurar un orden social deseado (González, 2016). Además, los discursos no se limitan únicamente a la política en un ámbito meramente institucional (partidos políticos, poder legislativo, economía, entre otros), sino que abordan lo político en su totalidad, es decir, todo aquello que permea y organiza la dinámica de las relaciones sociales (Mouffe, 1999), como lo es la moral, los movimientos y relaciones sociales, derechos humanos, la censura, etc.

En consecuencia, estos discursos comprenden posicionamientos políticos, éticos y morales específicos, que como se aclaró anteriormente, buscan el beneficio de una comunidad igual de definida y excluyente (González, 2016; Mudde, 2007). Así, al publicar que en relación con la maternidad hay cosas que nunca debieran cambiar (Acción Identitaria, 2019a), apelando al rol reproductivo que históricamente han desempeñado las mujeres, responde realmente a una clara articulación lógica racional, que busca ejercer una resistencia política a 
los cambios estructurales dentro de la sociedad, para lo cual recurre a posicionamientos políticos y éticos basados en los intereses de una sociedad tradicional y conservadora (Arendt, 1998; Gómez, 2017; Tilly, 1978). Por lo mismo es que al señalar que los valores cristianos y tradicionales de la sociedad chilena están en peligro (Ciudadanos Por Un Chile Mejor, 2019), o que el proyecto político nacionalista es capaz de hacerle frente al proyecto globalista (Partido Social Patriota, 2018), se manifiestan de manera suficientemente comprensibles para la audiencia las especificidades de los códigos políticos y morales ultraderechistas por los cuales se pretender generar un posicionamiento. De esta forma $-\mathrm{y}$ desde la filosofía de la crisis permanente e inminente-, se vuelve cada vez más claro cómo se apela a una sensación de inestabilidad del orden social y político, para así depositar la confianza en figuras de derecha, en este caso el Partido Social Patriota, autoproclamado capaz de resolver las problemáticas actuales (Gómez, 2017; Orjuela et al., 2017; Reguera, 2017).

\subsection{Estructura de la publicación}

Respecto de este punto, la Tabla 3 ofrece una síntesis de los aspectos relevantes.

Tabla 3

Síntesis de resultados de estructura de la publicación

\begin{tabular}{ll}
\hline Dimensión de análisis & Síntesis \\
\hline $\begin{array}{l}\text { Estructura de la } \\
\text { publicación }\end{array}$ & $\begin{array}{l}\text { Organización en torno a una imagen y un texto. } \\
\text { de captación primario y el texto permite } \\
\text { complementarlo narrativamente. }\end{array}$ \\
\hline
\end{tabular}

Fuente: Elaboración propia.

Ahora bien, la matriz permitió separar y visibilizar la estructura interna de los discursos, lo cual permite realizar ciertos lineamientos respecto de la articulación de la posverdad en las publicaciones. El primero de ellos remite a la organización interna de las publicaciones, a sus macroestructuras semánticas, esquemas discursivos y su nivel contextual. Así, el formato basal de las publicaciones se organiza en torno a alguna imagen y texto, donde el primero se consolida como método de captación primario, puesto que implica llamar la atención del usuario 
digital de una manera más efectiva, debido a la inmediatez con la cual entrega un mensaje. Empero, lo escrito presenta la posibilidad de explayarse acerca del discurso que se busca producir. Se entiende que la ultraderecha está al tanto de que esta imbricación de lo visual y lo escrito juega un papel importante en la efectividad de la producción de sus discursos en Facebook desde un punto de vista práctico y, por ende, emplea estrategias que priorizan el impacto de la publicación por sobre el contenido de la misma (Rojas, 2017).

Así, al incorporar una imagen que no solamente muestra el tweet que involucra al parlamentario Jackson, también se presenta un efecto de transparencia donde de fondo puede verse al diputado en cuestión (Corrupción Chile, 2019b). Con ello se pretende que al momento en que aparezca la publicación en el inicio de los usuarios, estos logren identificar visualmente a una figura pública que para la derecha representa una oposición política.

\subsection{Significados explícitos e implícitos}

La Tabla 4 expone los elementos más relevantes en torno a estos significados.

Tabla 4

Síntesis de resultados de los significados explícitos e implícitos

\begin{tabular}{ll}
\hline Dimensión de análisis & Síntesis \\
\hline & $\begin{array}{l}\text { El significado explícito corresponde al } \\
\text { discurso expositivo, esto es, las palabras } \\
\text { enunciadas y las imágenes mostradas; } \\
\text { mignificados explícitos e } \\
\text { implícitos }\end{array}$ \\
& la verdadera intencionalidad subliminal. \\
\hline
\end{tabular}

Fuente: Elaboración propia.

En todos los casos el significado explícito se encuentra de manera expositiva y de fácil acceso. Es el significado implícito, sin embargo, el que da cuenta del verdadero interés que persiguen los grupos de ultraderecha chilena, lo que se encuentra resguardado dentro del significado explícito (Van Dijk, 2003). Por ejemplo, al dictaminar el compromiso del pueblo venezolano con su propia patria, y que el deber de los jóvenes migrantes es retornar a su nación y retomar las riendas del destino y de su pueblo (Acción Identitaria, 2019b), se explicita que 
la salida de la población venezolana joven impide "derrocar al tirano" y, por ende, la solución del conflicto y la autonomía nacional. Incluso una frase reza "tu país te necesita", que rememora la política del Tío Sam y que, tomándose la potestad de actuar como vocero, clama que el país tiene aquella imperiosa necesidad.

Sin embargo, el interés implícito de Acción Identitaria busca resguardar a Chile de la migración masiva de población venezolana que se ha incrementado durante los últimos años. Así, un supuesto compromiso con la soberanía del pueblo venezolano oculta en realidad un interés político propio de carácter xenofóbico y nacionalista, ya que no solo se apela a detener el flujo migratorio que ingresa a Chile, sino que insta a que la población venezolana residente en el país regrese a Venezuela, arguyendo un profundo daño a la integridad de la nación cultural y socialmente, según la propia organización (Acción Identitaria, 2016). En este sentido, esta relación de significado explícito-implícito - abordada mediante la revisión de las publicaciones y del material para caracterizar el posicionamiento político de las organizaciones-, es una constante que es posible identificar en la totalidad de las publicaciones analizadas, guardando un control, selección y distribución procedural de los saberes y poderes del discurso (Foucault, 2005).

Así, todos los significados implícitos tienen por objetivo atacar, ridiculizar, criminalizar o deslegitimar otros discursos o figuras que no forman parte de las coordenadas políticas de la ultraderecha. Es por ello que cuando Ciudadanos Por Un Chile Mejor pretende informar que las diputadas comunistas presentaron un proyecto que busca censurar el humor en el Festival de Viña del Mar, detrás de ello se esconde una clara intención de ridiculizar y desprestigiar a las parlamentarias por su pertenencia al Partido Comunista (Ciudadanos Por Un Chile Mejor, 2016). Por eso se presenta el hecho de manera jocosa e insólita, insinuando un uso caprichoso de sus potestades legislativas tras verse afectadas personalmente, tal como ocurre también cuando se expresa que el diputado "hizo tremendo papelón" al equivocarse al citar a un autor en un debate económico y que fue desmentido por la persona aludida (Corrupción Chile, 2019b). Otro ejemplo aparece en el llamado a "despertar" para comprender que la toma del Instituto Nacional se debió al intento del FPMR de destruir "la bases culturales y los valores cristianos", en un supuesto plan de Gramsci (Ciudadanos Por Un 
Chile Mejor, 2019). Por último, la misma situación ocurre cuando se indica que el feminismo es una "corriente revanchista y odiosa" que propicia el "adoctrinamiento a niñas pequeñas para que desprecien el concepto de maternidad" y así "desprecien a sus hijos en gestación por lo tanto, abracen con facilidad la irresponsable causa abortista" (Acción Identitaria, 2019a), ya que contiene una clara intención de afectar negativamente la valoración social del exogrupo que hace peligrar el orden social (Gómez, 2017; Rodríguez, 2003).

En paralelo, esta relación entre los significados explícitos e implícitos pretende posicionar a los sectores de ultraderecha favorablemente frente a la opinión pública digital, como un sector con las respuestas necesarias y capaz de resolver las problemáticas que atañen a la sociedad chilena, la cual corre el peligro de corromper el orden establecido (Gómez, 2017; Orjuela et al., 2017).

La intervención realizada en las dependencias del Instituto Nacional de Derechos Humanos, INDH, bajo la consigna "recuperar Chile" ejemplifica lo anterior, ya que el Partido Social Patriota, PSP, pretende posicionarse como alternativa frente al proyecto globalista que dicha institución representa, tras "defender delincuentes por dinero" y por "minar la soberanía interior de la nación y evitar se haga justicia" (PSP, 2019). Así, sin explicitar verbalmente esta intención - y por medio de una habilidad comunicativa subliminal-, pretenden situarse como una entidad política comprometida, que busca plasmar en el inconsciente colectivo que son capaces de la acción política, jactándose de ello. El resto de publicaciones ofrece una dinámica similar, que proyecta una faceta de justicieros sociales comprometidos con los intereses de la nación:

- protectores de los valores tradicionales de la sociedad chilena, de la "infancia, la inocencia y el futuro del país" (Acción Identitaria, 2019a);

- que desenmascaran y exponen las mentiras y farsas de las figuras de la izquierda nacional (Corrupción Chile, 2019b);

- denunciantes de los hechos de corrupción e incongruencias del sector comunista (Ciudadanos Por Un Chile Mejor, 2016); o

- acusadores de la utilización de bebés como "escudos humanos" por parte del pueblo mapuche (Corrupción Chile, 2019a). 
Entonces, como se aprecia no solo se trata de deslegitimar a un enemigo, sino también de generar una valoración positiva en la opinión pública digital a costa de dicha perjuicio. Esto es visible nuevamente en la "lucha que se está dando en todo el mundo" entre globalismo y nacionalismo, al establecer que el primero encamina directamente a la "muerte, esclavitud y miseria para todos", mientras el nacionalismo se autoadjudica características que representan la "vida, libertad y autodeterminación", invitando incluso a votar por el proyecto político nacionalista (PSP, 2018): mientras el PSP demoniza la globalización, este se autopropone como la salida política a dicho proceso y a su crisis.

\subsection{Estructuras léxicas y sintácticas}

La Tabla 5 ofrece los resultados del análisis de estas estructuras.

Tabla 5

Síntesis de resultados de las estructuras léxicas y sintácticas

\begin{tabular}{ll}
\hline Dimensión de análisis & Síntesis \\
\hline & $\begin{array}{l}\text { Utilización de un lenguaje formulado con } \\
\text { intenciones políticas, un vocabulario simple }\end{array}$ \\
& y de fácil recepción para el usuario promedio. \\
Estructuras léxicas y & $\begin{array}{l}\text { No obstante, se establece lleno de significación } \\
\text { política que a su vez impacta en la viralización } \\
\text { del mensaje y no hay una responsabilidad }\end{array}$ \\
& $\begin{array}{l}\text { por parte de los autores en cuanto a las } \\
\text { implicancias de los conceptos utilizados. }\end{array}$ \\
\hline
\end{tabular}

Fuente: Elaboración propia.

Ahora bien, la articulación de la posverdad en las publicaciones queda expresada - y por ende expuesta - en sus estructuras lingüísticas, al develarse en función del qué y el cómo se dice, donde los discursos son expresados en un lenguaje formulado con una intencionalidad política. Por lo mismo, en la práctica la forma del mensaje posee un nivel de importancia igual o mayor al contenido del mismo (Illades, 2018; Llorente, 2017; Quirós, 2017), es decir, no se trata solamente de lo que se dice en concreto, sino de lo que realmente se quiere dar a entender. Es por ello que las publicaciones son escritas en vocabulario simple, de fácil acceso, sin conceptos complejos, pensadas para el sujeto común que es usuario de redes sociales y se espera que no deserte de la publicación. 
Por ejemplo, Acción Identitaria (2019b) se encarga de exponer el mensaje con palabras de uso cotidiano, pero publica una ilustración locutiva ${ }^{8}$ que enfatiza desde el inicio la importancia de distinguir "lo correcto de lo incorrecto o lo bueno de lo malo". Este despliegue tiene por objetivo no perder la atención del lector ni confundirlo con conceptos complicados -no es realmente medular lo que está leyendo, o al menos no importa si es verdadero o falso-; mientras la publicación haga sentido al usuario, esta permitirá consolidar las representaciones sociales inscritas en el discurso (Calvo y Aruguete, 2020; Prego, 2017; Quirós, 2017).

De igual modo, el vocabulario simple no implica necesariamente un lenguaje plano. De hecho, el léxico utilizado por las publicaciones analizadas aborda conceptos, palabras, nociones y recursos retóricos con una implicancia y significación altamente política. Lo relevante de esto radica en cómo la audiencia percibe el mensaje, cuestionando la carga semántica que yace tras las palabras (Hernández, 2017; Rojas, 2017).

Expresiones como las siguientes dan cuenta de una aguda selección de palabras en función de la viralización del mensaje, de modo que impacte en los usuarios, por ejemplo:

- "desnaturalizar las características inherentes de la feminidad como, por ejemplo, la belleza de la maternidad", para referirse al feminismo (Acción Identitaria, 2019a);

- “¿Quién se levantará contra el tirano? Tu país te necesita” al hablar de Maduro y el conflicto venezolano (Acción Identitaria, 2019b);

- "prohibir y regular a los humoristas del Festival de Viña del Mar", para denunciar una mala práctica de las diputadas (Ciudadanos Por Un Chile Mejor, 2016).

Es así que los emisores de estas publicaciones comprenden que los usuarios muestran interés en abordar e interiorizarse del contenido en cuestión, develando el poder de captación de los discursos producidos debido a la atención que despierta en la opinión pública (Amorós, 2018; Quirós, 2017), es decir, son atractivos porque lo polémico es atractivo, ya que alimenta el morbo de la audiencia (Ponce-Tarré, 2018). Desde esta perspectiva, gran parte de los sucesos controversiales que involucran las

8 Esto implica que el interlocutor entiende todas las palabras que componen una secuencia lingüística. 
esferas sociales con poder dentro de la sociedad o que lo disputan, se presentan como apetecibles para las masas (Thompson, 2001). Por ello, cuando se trata de un tema sensible como el de la comunidad mapuche, la utilización de bebés como escudos humanos (Corrupción Chile, 2019a) despierta el interés de los usuarios, porque históricamente la comunidad mapuche ha disputado espacios políticos al Estado de Chile y, por lo fuerte que es el hecho mismo que se atente contra la integridad física de infantes, se vuelve doblemente controversial.

\subsection{Recursos retóricos}

En cuanto a los recursos retóricos, la Tabla 6 sintetiza los elementos más relevantes.

Tabla 6

Síntesis de los resultados de los recursos retóricos

\begin{tabular}{ll}
\hline Dimensión de análisis & Síntesis \\
\hline & Buscan dar una aparente solidez argumentativa \\
& y locutiva a la publicación. Las metáforas son \\
& utilizadas para enmascarar la intención del \\
Recursos retóricos & autor y generar un impacto en la audiencia. \\
& La hipérbole ayuda a presentar escenarios \\
& devastadores para generar un rechazo o temor \\
& en la audiencia respecto de un exogrupo. \\
\hline
\end{tabular}

Fuente: Elaboración propia.

Respecto del mismo carácter atractivo, es posible encontrar metáforas o eufemismos/hipérboles que, paralelamente, buscan darle una aparente solidez argumentativa y locutiva al discurso. Estos recursos se encuentran cargados de exacerbaciones y una vehemencia narrativa y visual constante, con uso de mayúsculas, signos de exclamación y recursos visuales. En torno al uso de metáforas, estas son utilizadas principalmente para enmascarar la intención del autor y lograr cierto impacto en la audiencia. Así, al aseverar que "ningún liceo emblemático quedará en pie tras el plan del FPMR" (Ciudadanos Por Un Chile Mejor, 2019), se busca asociar la destrucción que representan el FPMR y la doctrina comunista para la estabilidad (material y simbólica) de la sociedad. De igual forma, plantear como "motores de cambio" a los jóvenes venezolanos - puesto que solo ellos podrían hacer "la toma soberana del poder y las riendas de su destino" en Venezuela (Acción 
Identitaria, 2019b)—, establece una asociación a llamar a la población venezolana a no dejar su país ni venir a Chile en pos de retomar sus propios asuntos nacionales.

Lo mismo sucede al plantear el globalismo como "muerte, esclavitud y miseria para todos" y utilizar una tipografía que chorrea sangre (PSP, 2018); "recuperar Chile" implicando al país como secuestrado por el globalismo (Partido Social Patriota, 2019); o bien, presentar a las diputadas Vallejo y Cariola en medio de los billetes volando y cajas fuertes abiertas (Ciudadanos Por Un Chile Mejor, 2016), ya que estas publicaciones dan cuenta de manipulación mediática y discursiva (Calvo y Aruguete, 2020; Illades, 2018; Llorente, 2017; Quirós, 2017).

En cuanto a las hipérboles, la incorporación de este recurso retórico funciona particularmente al plantear un escenario catastrófico, de desolación, con contradicciones políticas, hechos condenables moralmente o recurrir directamente al miedo. De esta forma, el interlocutor se encuentra en constante interpelación por parte de diferentes actores, adjudicándoles los conflictos presentados. La hipérbole cumple el fin de apoyar la construcción del proyecto político a través de la deslegitimación del otro, priorizando la locución y forma del mensaje por sobre la razón (Gómez, 2017; Orjuela et al., 2017).

\subsection{Dimensión interaccional}

Finalmente, los elementos más relevantes de esta dimensión se expresan en la Tabla 7.

Tabla 7

Síntesis de los resultados de la dimensión interaccional

\begin{tabular}{ll}
\hline Dimensión de análisis & Síntesis \\
\hline & $\begin{array}{l}\text { Comunicación unidireccional, con un } \\
\text { solo interlocutor. Casi la totalidad de las } \\
\text { publicaciones presenta un solo orador, quien } \\
\text { simultáneamente es el autor. La sección de }\end{array}$ \\
& comentarios ofrece discusiones por parte de \\
Dimensión & los usuarios, pero los autores no se manifiestan \\
ninteraccional & mensaje que se esparce por medio de las redes \\
& sociales, pero sin hacerse responsables por el \\
& contenido compartido por otros. \\
\hline
\end{tabular}

Fuente: Elaboración propia. 
En relación con la dimensión interaccional - que consiste en la distribución temática y turnos de habla- es posible establecer que las publicaciones en su totalidad comparten la categoría de comunicación unidireccional, esto es, existe solo un interlocutor que entrega el mensaje. Salvo dos casos, el resto de las publicaciones contiene un único orador que, a su vez, es autor de la misma. Por último, si bien Facebook permite la sección de comentarios donde los usuarios pueden generar una discusión, en las publicaciones analizadas los autores no toman participación del proceso. Esto da cuenta de un discurso político de los grupos de ultraderecha que es producido en redes sociales, pero donde no se hacen cargo de las posibles implicancias que se generan, ni menos toman responsabilidad del contenido que imparten.

Pese a esta ausencia, sí existe una especie de discusión en la sección de comentarios. En efecto, si bien la mayor cantidad de comentarios expresan adhesión al contenido y al discurso publicado, también se producen otros comentarios de los usuarios de la red social que cuestionan la veracidad y mala intención de las publicaciones. Lo anterior permite forjar la idea del usuario como un agente activo y crítico en los nuevos espacios de comunicación digital para la disputa discursiva e ideológica (Hernández, 2017; Lasén y Puente, 2016; Rojas, 2017).

\section{Discusión y conclusiones}

Las imbricaciones estudiadas han evidenciado que la utilización de posverdad no resulta una práctica aislada, ya que tanto los medios informales de comunicación como las organizaciones políticas de ultraderecha la utilizan para producir y reproducir discursos políticos en la conocida red social. En concreto, la ultraderecha chilena hace uso constante de un populismo renovado en un espacio joven en pos de moldear la opinión pública, por medio de una estrategia de acción colectiva racional que llevan a procesos de socialización e información críticos y de largo alcance en el ágora digital que representa Facebook (Gómez, 2017; Laclau, 2005; Tilly, 1978).

Dicha estrategia de acción colectiva se decanta por medio de un enfoque pragmático que apela a lo político (Mouffe, 1999), que comprende la plataforma digital lo suficientemente bien como para posibilitar la circulación y materialidad de sus discursos - y su poder- (Fou- 
cault, 2005) en la audiencia digital, sin necesidad del recurso teórico para legitimarse. Así, se establece que la ultraderecha no necesariamente conoce de manera exhaustiva la teoría que subyace tras las relaciones sociodigitales, o incluso que comprenden los aspectos teóricos detrás de Internet como tales, empero vislumbran bien la posibilidad que les brinda este espacio para sus fines políticos.

Esto es de suma importancia, puesto que confirma el carácter meramente instrumental que le otorga la extrema derecha a la posverdad (y a Internet) por medio de una colonización de los afectos, saberes, sentimientos y de una desterritorialización de sentidos que se encuentran dentro del imaginario ultraderechista (Beasley-Murray, 2010; Berardi, 2007; Foucault, 2002). La visión y misión que se plantea este grupo son caracterizadas por una acción política-colectiva que prioriza el impacto que pueda causar en la opinión pública digital, por medio de la efectividad de sus saberes y significados producidos (Foucault, 2005; Hine, 2004; Tilly, 1978). Para este sector, en espacios como Internet no es necesaria la coerción mientras se trabaje profusamente el plano ideológico, apelando directamente a la audiencia en un nivel cognitivo (Beasley-Murray; 2010; Berardi, 2007). Desde esta óptica, la ultraderecha comprende que no es necesariamente importante pensar el contenido publicado, sino relevar ciertos saberes y poderes, desde una perspectiva foucaultiana, en espacios con tanta capacidad de agencia crítica, pero tan poco control como Internet (Mazzone, 2018).

Por su parte, la identificación de los discursos políticos producidos a través de la posverdad da cuenta de contenidos altamente ideológicos e ideologizados, con una actitud de predisposición, esto es, una especie de discurso prefabricado que busca minimizar la mayor cantidad de instancias de análisis crítico. Similarmente, estos discursos son controversiales y apelativos en la medida en que despiertan un interés en la opinión pública digital, pero sin buscar despertar el interés suficiente como para cuestionar el contenido publicado desde una actitud crítica (Foucault, 1995; Hernández, 2017). Por ello, la investigación se permite proyectar una perspectiva analítica en pos de cuestionar el protagonismo de la sociedad del espectáculo en la cual se desenvuelven estos discursos, siendo estos víctimas de la mercantilización de la vida social, atados a una banalización de sí mismos y reemplazados 
por las representaciones que hace la experiencia colectiva de los mismos (Baudrillard, 1983; Debord, 1967). Así, la selección de estos discursos aprovecha la cultura del morbo y del consumo de lo controversial para influir en la opinión pública, mediando a los usuarios no solo a través del poder en los discursos, sino a través de las imágenes que estos mismos proyectan debido a la compenetración cultural de los dispositivos tecnológicos digitales en la vida cotidiana (Debord, 1967; Foucault, 2005; Simondon, 2007).

A su vez, el análisis de los componentes internos de los discursos permitió comprender cómo estos se articulan racionalmente al operacionalizar la posverdad, siguiendo pasos lógicos en función de los objetivos colectivos. Se recalca la utilización sostenida de la captación y apelación visual; y el uso de lenguaje y retórica populista atractiva para la audiencia: lenguaje simple, pero rico en contenido político e ideologizado para esconder sus intenciones en apariencia bien intencionadas. Se establece que el proyecto político de la ultraderecha chilena en lo digital se construye a través de la deslegitimación de otras posiciones, pues utiliza la posverdad como un repertorio de acción para la consolidación de representaciones sociales de los distintos sujetos que se ven involucrados en el relato, basándose netamente en la apelación a sentimientos y subjetividades de la audiencia, no en hechos, evidencias o investigaciones que den cuenta y respalden su discurso. De esta forma, no se trata solamente de cómo se representa a un exogrupo, sino de cómo se expresa esa representación por medio de la capacidad del lenguaje para crear realidades, conjunto de saberes y poderes (Deleuze, 1990; Foucault, 2005; Ponce-Tarré, 2018; Rojas, 2017; Van Dijk, 2003; Zizek, 2003).

Es por medio de un lenguaje cargado de posverdad que se establecen los discursos explícitos (de los cuales se develan los implícitos), la predisposición de una actitud frente a las representaciones sociales, las relaciones establecidas entre los sujetos, los esquemas discursivos, y la forma en que la ultraderecha chilena produce los discursos políticos en Facebook (Álvarez, 2018; Moscovici, 2000; Quirós, 2017; Rojas, 2017; Van Dijk 2003). La posverdad, entonces, permea la publicación totalmente, es decir, no solo se utiliza, sino que la publicación en sí se presenta como una instancia de posverdad, donde lo verdadero no significa algo necesario para sostener un discurso (Tesich, 1992). 
La importancia de ello recae en que la ultraderecha busca justamente instrumentalizar estas instancias de posverdad, esto es, aprovechar los algoritmos de la plataforma para mantenerse relevante en el debate político que se lleva a cabo dentro del contexto digital. Es por ello que este sector ha comenzado a disputar las redes sociales digitales, puesto que entiende que estas magnifican la posibilidad del accionar colectivo y de enunciación (Deleuze, 1990; Foucault, 2002) por su capacidad de organización remota a gran escala, sin un compromiso físico o incluso de identificación, gracias al anonimato que brinda Internet (Rojas, 2017).

Puesto que se insiste en que este sector político maneja dicha información al menos a un nivel práctico, es necesario sumar el hecho que el sujeto-usuario de Facebook desarrolla su vida en la plataforma digital recluido dentro de burbujas informativas, estableciendo una relación proporcionalmente directa entre el contenido políticamente atractivo y la cantidad de publicaciones similares que se mostrarán en el inicio de Facebook, debido a algoritmos destinados a reforzar sus intereses y creencias, de modo que existe una seria predisposición a concordar con los saberes y significados de la publicación, incluso antes de ser vista por el usuario (Calvo y Aruguete, 2020; Prego, 2017; Quirós, 2017).

Así, la ultraderecha aprovecha esta cadencia de sucesos donde se le suministran al usuario publicaciones porque son atractivas, y debido a que los algoritmos anticipan, predicen e intentan predisponer comportamientos, vuelven a suministrarle más publicaciones similares, apelando a los intereses conscientes e inconscientes que manifiesta el sujeto (Calvo y Aruguete, 2020; Rivera, 2020; Prego, 2017). Todo esto permite interpretar una voracidad en el repertorio de acción ultraderechista, que implica aferrarse a todos los recursos disponibles para posicionarse en la disputa.

Por último, dada la relevancia coyuntural de esta investigación es necesario situar y proyectar el contexto político del levantamiento popular de octubre de 2019 en contra del modelo neoliberal que constriñe física y mentalmente a la sociedad chilena, alzándose como categoría emergente de análisis de la política y articulación digital. Ahora bien, sin un análisis de casos en profundidad resulta impertinente realizar conjeturas, pero las ideas preliminares que propone el presente 
trabajo implican una intensificación y transmutación de la posverdad en torno al proceso de la revuelta social. En este aspecto, se ha visto a la extrema derecha chilena canalizar el uso de posverdad y las fake news con la intención de poner resistencia, cambiando incluso su propio discurso; y es claro al ver cómo José Antonio Kast en Twitter alega ser la resistencia, que son muchos más, que en silencio y con humildad seguirán trabajando por Chile (Kast, 2020), lo que hace entrar en conflicto la narrativa del grupo desposeído, excluido del sistema, invistiéndose de significados que apelan a la identificación con los desvalidos para encubrir su intención de perpetuar la dominación que sostiene su propio sector (Orjuela et al., 2017; Yehiya, 2017).

De igual manera tras la aparición de propaganda digital a favor del apruebo para una nueva constitución, surgieron publicaciones en pos del rechazo y que apelan netamente al miedo o al desconocimiento de la audiencia en torno al proceso constituyente, así como también articulan la filosofía de la crisis permanente e inminente (Reguera, 2017; Sanahuja, 2019).

Otra suposición es que la ultraderecha busca establecer representaciones sociales negativas en torno a una nueva constitución, a los actores políticos que la impulsan y al movimiento popular que se gestó con efervescencia política y social; así mismo, desea posicionarse como la opción válida en el proceso constituyente, pues representa los verdaderos valores de la nación que peligran por amenazas internas y externas. Esto, por medio de la misma retórica alarmante y populista, con una cuidadosa selección de tópicos y figuras para causar un mayor impacto en la audiencia.

Complementariamente es pertinente mencionar el ascenso de cuentas de fact-checking que hoy en día operan en las plataformas digitales como Facebook o Instagram y que se encargan específicamente de realizar una verificación de la información que circula en la red, en especial a raíz de la cantidad de posverdad y fake news que comenzó a circular en el contexto posterior al estallido social en el caso nacional. Si bien hoy esto puede parecer una sucesión lógica de eventos, habla directamente de lo instantáneo que se vuelven las repercusiones políticas que inciden en las subjetividades envueltas en un contexto de efervescencia política (Berardi, 2009). En cierto sentido la noción de fact-checking, en el contexto nacional luego del 18 de octubre de 2019 
rememora al concepto de posverdad, ya que ambos se volvieron relevantes en un proceso de discontinuidad histórica (Foucault, 1968), adquiriendo un nuevo significado en un nuevo contexto y de igual manera incidiendo en la actitud y prácticas referentes a la vida digital (Tesich, 1992). A su vez, este proceso de verificación de datos plantea nuevos desafíos en torno a la comunicación, política e Internet. Incluso plataformas como Facebook e Instagram han realizado esfuerzos para incorporar distintos mecanismos para prevenir la malinformación y robustecer los algoritmos que detectan contenido que pueda considerarse engañoso.

A modo de cierre, estimamos que la posverdad no solo llegó para quedarse, sino que su existencia se ha instalado en la psique de las prácticas sociales cotidianas, y la comunidad digital parece haberlo interiorizado y normalizado. Esto es, que las expectativas y representaciones mentales que se generan a partir del concepto de Internet y redes sociales suponen siempre la existencia implícita (o al menos una gran probabilidad de esta) de posverdad. Ello no significa pensar que todo contenido digital es posverdad, pero sí implica considerar que en todo contenido existe la probabilidad de esta emerja.

Hoy, pensar Internet sin posverdad resulta un ejercicio imposible y utópico. Años atrás, antes de la masificación del concepto como tal, efectivamente se poseía conocimiento de que este fenómeno existía dentro de Internet, por lo mismo el desarrollo del mundo digital se ha ido forjando con tal idea presente en su subconsciente: noticias falsas, verdades a medias, sensacionalismo por sobre los hechos, etc. Es por ello que el paso lógico es que ese mundo haya alcanzado una madurez en cuanto a su compenetración en la vida social, manteniendo el fenómeno.

De esta forma las proyecciones finales que se estipulan aquí implican repensar una sociología desde lo digital, y no solo para lo digital. Comprender esta distinción supone aceptar un punto de no retorno en cuanto a la imbricación tecnología y la vida social (Beasley-Murray, 2010; Berardi, 2007; Hine, 2004; Lasén y Puente, 2016). De igual forma este posicionamiento debe considerar lo teórico sin nunca dejar lo práctico o empírico a un lado, ya que permite develar el comportamiento y relaciones que subyacen a las subjetividades en el capitalismo digital. 


\section{Referencias}

Acción Identitaria Chile. (2016). Identidad y justicia. El programa político de Acción Identitaria. Recuperado de http://media.wix. com/ugd/3650cf_801633874ec4411a9b7f85af8adf12f5.pdf.

Acción Identitaria [Accion-Identitaria]. (25 de febrero de 2019a). En algunas oportunidades, para la naturaleza humana es difícil distinguir lo correcto de lo incorrecto o lo bueno de lo malo. Facebook. Recuperado de https://www.facebook.com/accionid/photos/a.598451116885782/2308871082510435/?typ $\mathrm{e}=3 \&$ theater

Acción Identitaria [Acción-Identitaria]. (10 de julio de 2019b). Venezuela es un país riquísimo, cooptado por una narco dictadura y saqueado por potencias emergente. Facebook. Recuperado de https://www.facebook.com/accionid/photos/a.6963629 03761269/2537885442942330/?type=3\&theate

Almeyda, R. [@Renealmeyda1]. (s.f.). Inicio. Recuperado de https:// twitter.com/renalmeydal

Althusser, L. (1974). Ideología y aparatos ideológicos de Estado. Buenos Aires: Ediciones Nueva Visión.

Álvarez, M. (2018). Estado del arte: posverdad y fake news (Tesis de maestría inédita). Universidad Nacional de Educación a Distancia, Madrid, España.

Amorós, M. (2018). Fake news. La verdad de las noticias falsas. Barcelona: Plataforma Actual.

Arendt, H. (1998). Los orígenes del totalitarismo. Madrid: Santillana Ediciones.

Barolin, E. (2017). El ascenso de la derecha en América Latina: apuntes para su discusión. Contexto Internacional, 17(42), 21-26. Recuperado de http://www.fundamentar.com/archivos/publicaciones/contexto_internacional/pdf/CI\%2042/3.pdf

Baudrillard, J. (1983). Simulacra and simulation. Michigan: Los Angeles.

Beasley-Murray, J. (2010). Poshegemonía: Teoría política y América Latina. Buenos Aires: Paidós.

Berardi, F. (2007). Generación post-alfa: Patologías e imaginarios en el Semiocapitalismo. Buenos Aires: Tinta Limón Ediciones.

Berardi, F. (2009). The soul at work. Los Angeles: Semiotext. 
Berckemeyer, F. (2017). La mentira de la posverdad. UNO, 27, 26-27. Recuperado de https://www.revista-uno.com/wp-content/ uploads/2017/03/UNO_27.pdf

Birkbak, A. y Carlsen, H. (2016). The world of edge rank: Rhetorical Justifications of Facebook's news feed algorithm. Cотрutational Culture, 5. Recuperado de https://ssrn.com/abstract $=2764210$

Boltanski, L. y Chiapello, E. (2003). El nuevo espíritu del capitalismo. Madrid: Akal Ediciones.

Calvo, E. y Aruguete, N. (2020). Fake news, trolls y otros encantos. Cómo funcionan (para bien y para mal) las redes sociales. Buenos Aires: Siglo XXI Editores.

Canales, M. (2006). Metodologías de investigación social. Santiago de Chile: LOM Ediciones.

Castells, M. (2014). El impacto de Internet en la sociedad: una perspectiva global. En BBVA (Ed.), C@mbios: 19 ensayos clave acerca de cómo Internet está cambiando nuestras vidas (pp. 127-148). Recuperado de https://www.bbvaopenmind. com/wp-content/uploads/2014/01/BBVA-OpenMind-libroCambio-19-ensayos-fundamentales-sobre-c\%C3\%B3mointernet-est\%C3\%A1-cambiando-nuestras-vidas-Tecno$\log \% \mathrm{C} 3 \%$ ADa-Interent-Innovaci\%C3\%B3n.pdf

Chillón, A. (2017). El concepto de 'facción': índole, alcance e incidencia en los estudios periodísticos y literarios. Cuadernos.Info, 40, 91-105. Recuperado http://cuadernos.info/index.php/ CDI/article/view/cdi.40.1121

Ciudadanos Por Un Chile Mejor. [Ciudadanos-Por-Un-Chile-Mejor] (s.f.). Inicio. Facebook. Facebook. Recuperado de https:// www.facebook.com/pg/Ciudadanos-Por-Un-Chile-Mejor-804910709577172/about/?ref=page_internal.

Ciudadanos Por Un Chile Mejor. [Ciudadanos-Por-Un-Chile-Mejor]. (28 de febrero de 2016). A ESTAS DOS COMUNISTAS LES DOLIÓ QUE LES DIERAN EN LOS CACHOS... Camila Vallejo y Karol Cariola, presentaron proyecto para prohibir y regular a los humoristas en el Festival de Viña. Facebook. Recuperado de https://www.facebook.com/804910709577172/photos/a.106 0288040706103/993692800698961/?type=3\&theater

Ciudadanos Por Un Chile Mejor. [Ciudadanos-Por-Un-Chile-Mejor]. (8 de julio de 2019). ASÍ SIGUEN DESTRUYENDO LAS 
BASES CULTURALES DE NUESTRA SOCIEDAD. Y LOS INGENUOS LES COMPRAN EL. CUENTO! ES EL PLAN DE ... Facebook. Recuperado de https://www.facebook. com/804910709577172/photos/a.867431466658429/229099 $0997635795 /$ ?type $=3 \&$ theater

Corbillón, C. (2018). Estudio de la posverdad y las fake news en relación con la crisis catalana del 1-O (Tesis de grado). Universidad de Valladolid, Valladolid, España.

Corrupción Chile. [CorrupcionChile]. (s.f.). Inicio. Facebook. Recuperado de https://www.facebook.com/CorrupcionChile/

Corrupción Chile. [CorrupcionChile]. (21 de marzo de 2019a). \#ENLASREDES| Comunidades mapuches usaron como escudos humanos a bebes en las protestas de ayer en Temuco. Indignante. Facebook. Recuperado de https://www.facebook. com/CorrupcionChile/photos/a.412790178893991/1182901 038549564/?type $=3 \&$ theater.

Corrupción Chile. [CorrupcionChile]. (5 de junio de 2019b). \#ENLASREDES | Mega fail de Giorgio Jackson, el diputado del Frente Amplio mandó a leer a un twittero y citó a varios economistas... Facebook. Recuperado de https://www.facebook.com/ CorrupcionChile/photos/a.412790178893991/12366385098 $42483 /$ ?type $=3 \&$ theater

Debord, G. (1967). La sociedad del espectáculo. Santiago de Chile: Quattrocento.

Deleuze, G. (1990). ¿Que es un dispositivo? En E. Balbier, G. Deleuze, H. Dreyfus, M. Frank, A. Glucksmann, G. Lebrun, R. Machado, J. Miller, M. Morey, J. Rajchman, R. Rorty, F. Wahl, y otros (Eds.), Michel Foucault, Filósofo (pp. 155-163). Barcelona: Gedisa Editorial.

De Angelis, C. (2017). Ascenso de la posverdad o cómo construir dioses a medida. UNO, 27, 38-39. https://www.revista-uno.com/ wp-content/uploads/2017/03/UNO_27.pdf

Eagleton, T. (1997). Ideología: una introducción. Barcelona: Editorial Paidós.

Fernández, V. (2011). Balance de los estudios culturales en América Latina. La ruta de la comunicación en la definición de objeto. Nómadas. Revista Crítica de Ciencias Sociales y Jurídicas, $0(0)$, 359-380. https://doi.org/10.5209/rev_noma.2011.37960 
Fernández-García, N. (2017). Fake news: una oportunidad para la alfabetización mediática. Nueva Sociedad, 269, 66-67. Recuperado de http://www.iade.org.ar/system/files/5.tc_fernandez_269_0.pdf.

Foucault, M. (1968). Las palabras y las cosas: una arqueología de las ciencias humanas. Buenos Aires: Siglo XXI Editores.

Foucault, M. (1995). Crítica y Aufklärung. Revista De Filosofía ULA, 8, 1-18. Recuperado de http://www.saber.ula.ve/bitstream/ handle/123456789/15896/davila-critica-aufklarung.pdf;js essionid=5C1229419ED94725F79A3DFC66F9FBF4?sequen ce $=1$

Foucault, M. (2002). La arqueología del saber. Buenos Aires: Siglo XXI Editores.

Foucault, M. (2005). El orden del discurso. Buenos Aires: Fábula Tusquets Editores.

Fowks, J. (2017). Mecanismos de la posverdad. Lima: Fondo de Cultura Económica.

Fuchs, T. y Schäfer, F. (2020). Normalizing misogyny: Hate speech and verbal abuse of female politicians on Japanese Twitter. Japan Forum, O(0), 1-27. https://doi.org/10.1080/09555803.2019.1 687564

Gómez, M. (2017). La comunidad imaginada de la derecha nacionalpopulista. Revista internacional del Pensamiento Político, 12, 261-281. Recuperado de https://www.upo.es/revistas/ index.php/ripp/article/view/3238/2516.

González, J. (2016). La retórica de lo extremo en la ultraderecha chilena. Hallazgos, 14(27), 19-41. Recuperado de http://www. scielo.org.co/pdf/hall/v14n27/1794-3841-hall-14-27-00019. pdf.

Gruppi, L. (1978). El concepto de Hegemonía en Gramsci. México, D.F.: Ediciones de Cultura Popular.

Hernández, A. (2017). Resiliencia de la organización de la información en la era de la posverdad. Alcance. Revista Cubana de Información y Comunicación, 6(14), 47-59. Recuperado de http:// scielo.sld.cu/scielo.php?script=sci_arttext\&pid=S241199702017000300004\&lng=es\&tlng=es

Hine, C. (2004). Etnografía virtual. Barcelona: Editorial Universitat Oberta Catalunya, UOC. 
Horkheimer, M. y Adorno, T. (1998). Dialéctica de la ilustración. Madrid: Trotta.

Illades, E. (2018). Fake News. La nueva realidad. México, D.F.: Grijalbo. Internet World Stats. (2020). Facebook users in the world. Facebook usage and Facebook growth statistics by world geographic regions. Recuperado de https://www.internetworldstats. com/facebook.htm.

Juventud Social Patriota. [JuventudSocialPatriota] (2019). Inicio. Facebook. Recuperado de https://www.facebook.com/pg/JuventudSocialPatriota/about/?ref=page_internal.

Kast, J.A. [@joseantoniokast]. (9 de enero de 2020).Somosla Resistencia. Somos muchos. Somos más. En silencio y con humildad. Sigamos trabajando por Chile! Twitter. Recuperado de https:// twitter.com/joseantoniokast/status/1215416069071962112

Keyes, R. (2011). The post-truth era: Dishonesty and deception. New York: St. Martin's Press.

Laclau, E. (2005). La razón populista. Buenos Aires: Fondo de Cultura Económica.

Lasén, A. y Puente, H. (2016). La cultura digital. Tecnologías sociales de la comunicación. materiales docentes de la UOC. Módulo Didáctico 3. 1-45. Recuperado de https://www.researchgate. net/profile/Amparo_Lasen/publication/305446340_La_cultura_digital/links/578f6af008ae35e97c42731e/La-culturadigital.pdf.

Llorente, J. (2017). La era de la posverdad: realidad vs. percepción. UNO, 27, 8-9. Recuperado de https://www.revista-uno.com/ wp-content/uploads/2017/03/UNO_27.pdf.

Markham, A. y Buchanan, E. (2012). Ethical decision-making and internet research recommendations from the AoIR Ethics Working Committee (Version 2.0). Recuperado de https://aoir. org/reports/ethics2.pdf.

Marx, C. y Engels, F. (1974). La ideología alemana. Barcelona: Ediciones Grijalbo.

Mazzone, D. (2018). Máquinas de mentir. "Noticias falsas" y "posverdad". Buenos Aires: Crujía Ediciones.

Mejía, J. (2014). El muestreo en la investigación cualitativa. Investigaciones Sociales, 4(5), 165-180. https://doi.org/10.15381/ is.v4i5.6851. 
Moscovici, S. (2000). Social representations. Explorations in social psychology. Cambridge: Cambridge Polity Press.

Mouffe, Ch. (1999). El retorno de lo político. Barcelona: Editorial Paidós.

Mudde, C. (2007). The ideology of the extreme right. New York: Manchester University Press.

Murillo, F. J. y Martínez-Garrido, C. (2010). Investigación etnográfica. Madrid: Universidad Autónoma de Madrid, UAM.

Nagle, A. (2017). Kill all normies: Online culture wars from 4chan and Tumblr to Trump and the Alt-Right. Croydon: Zero Books.

Orjuela, L. J., Chagas-Bastos, F. H., y Chenou, J.-M. (2017). El incierto "efecto Trump" en el orden global. Revista de Estudios Sociales, 35(61), 107-111. https://doi.org/10.7440/res61.2017.09.

Oxford English Dictionary. (2016). Post-truth. Recuperado de https:// en.oxforddictionaries.com/definition/post-truth

Partido Social Patriota [Partido-Social-Patriota]. (13 de septiembre de 2018). Ha quedado claro. La lucha que debemos librar es de Globalismo contra nacionalismo. En todo el mundo se da exactamente... Facebook. Recuperado de https://www.facebook. com/PartidoSocialPatriota.chile/posts/2380634915281709

Partido Social Patriota [Partido-Social-Patriota]. (10 de octubre de 2019). Les dejamos a los globalistas del INDH varios sacos de dinero y un mensaje. "Aquí está el pago por defender... Facebook. Recuperado de https://www.facebook.com/PartidoSocialPatriota.chile/posts/3343955238949667

Pina, C. (2017). Amigos de la verdad: los límites jurídicos de las fake news. UNO, 27, 36-37. Recuperado de https://www.revistauno.com/wp-content/uploads/2017/03/UNO_27.pdf

Ponce-Tarré, E. (2018). La posverdad y la violencia mediática. Estrategas. Investigación En Comunicación, 5, 37-52. Recuperado de http://marketing.udla.edu.ec/ojs/index.php/estrategas/ article/view/151

Prego, V. (2017). Burbujas Informativas. UNO, 27, 20-21. Recuperado de https://www.revista-uno.com/wp-content/ uploads/2017/03/UNO_27.pdf

Quirós, E. (2017). Fake news v/s periodismo libre e independiente. UNO, 27, 36-37. Recuperado de https://www.revista-uno. com/wp-content/uploads/2017/03/UNO_27.pdf 
Reguera, M. (2017). Alt Right: radiografía de la extrema derecha del futuro. Contexto y Axión, 105, 1-29. Recuperado de https:// ctxt.es/es/20170222/Politica/11228/Movimiento-Alt-RightEEUU-Ultraderecha-Marcos-Reguera.htm

Rivera, D. (2018). Internet y su potencial político: hacktivismo en Anonymous Chile (2011-2016). Revista F@ro, 1(27), 86-116. Recuperado de https://www.revistafaro.cl/index.php/Faro/ article/view/542.

Rivera, D. (2020). Socialización mediante algoritmos: de los sistemas de recomendaciones a las predicciones. En A. Tello (Editor), Tecnología, política y algoritmos en América Latina (pp.147 156). Viña del Mar: Cenaltes Ediciones.

Rodríguez, O. (2003). El presente de la derecha y la ultraderecha en el mundo. Revista Mexicana de Ciencias Políticas y Sociales, 46(187), 177-201. Recuperado de https://www.redalyc.org/ pdf/421/42118707.pdf.

Rodríguez, S. y Sánchez, M. (2013). La extrema-derecha en Facebook. España 2000 y Democracia Nacional durante la campaña electoral de 2011. Revista Mediterránea de Comunicación, 4(1), 221-258. https://doi.org/10.14198/medcom2013.4.1.10

Rojas, L. (2017). Mentir es la nueva verdad: la posverdad en la comunicación (Tesis de grado). Universidad de Santo Tomás, La Paz, Bolivia. Recuperado de https://underpost.net/ir/pdf/ posverdad/posverdad-en-la-comunicacion.pdf

Sanahuja, J. (2019). Crisis de la globalización, el regionalismo y el orden liberal: el ascenso mundial del nacionalismo y la extrema derecha. Revista Uruguaya de Ciencia Política, 28(1), 5994. http://dx.doi.org/10.26851/rucp.28.1.3

Silva, A. y Pizarro, V. (2020). La posverdad como repertorio de acción de la ultraderecha para la producción de discursos sociales en Facebook (Tesis de pregrado). Universidad de Valparaíso, Valparaíso, Chile.

Simondon, G. (2007). El modo de existencia de los objetos técnicos. Buenos Aires: Prometeo Libros.

Tiempo Devorado. (2017). De la derecha a la ultraderecha. Nuevos discursos, nuevas tribunas. Tiempo Devorado. Revista de Historia Actual, 4(1), 230-233. Recuperado de http://revistes.uab. cat/tdevorado/article/view/v4-n1-redaccion2/pdf_95

Tesich, S. (1992). A government of lies. The Nation, 6(13), 12-14. 
Thompson, J. (2001). El escándalo político. Barcelona: Paidós.

Tilly, C. (1978). From mobilization to revolution. New York: Random House.

Van Dijk, T. (2003). Ideología y discurso. Barcelona: Ariel.

Van Dijk, T. (2016). Análisis crítico del discurso. Revista Austral de Ciencias Sociales, 30, 202-233. https://doi.org/10.4206/rev. austral.cienc.soc.2016.n30-10

Van Erkel, P. y Van Aelst, P. (2020). Why don't we learn from social media? Studying effects of and mechanisms behind social media news use on general surveillance political knowledge. Political Communication, 1-19. https://doi.org/10.1080/105 84609.2020.1784328

Wang, M., Nguyen, N., Dai, S., Chi, P. y Dow, C. (2020). Understanding potential cyber-armies in elections: A study of Taiwan. Sustainability, 12(6), 22-48. http://doi:10.3390/su12062248.

Yehya, N. (2017). La extrema derecha digital y el ocaso de la ilustración. Letras Libres, 19(221), 34-35. Recuperado de https://www.letraslibres.com/mexico/revista/la-extrema-derecha-digitaly-el-ocaso-la-ilustracion-derechas-un-imperio

Zarzalejos, J. (2017). Comunicación y periodismo y 'fact-checking. UNO, 27, 11-13. Recuperado de https://www.revista-uno. com/wp-content/uploads/2017/03/UNO_27.pdf.

Zeyu, L. (2019). Towards an understanding of online extremism in Japan. Trabajo presentado en la IEEE/WIC/ACM International Conference on Web Intelligence-Companion Volume, Thessaloniki, Greece. https://doi.org/10.1145/3358695.3360922.

Zizek, S. (2003). El sublime objeto de la ideología. Buenos Aires: Siglo XXI Editores. 


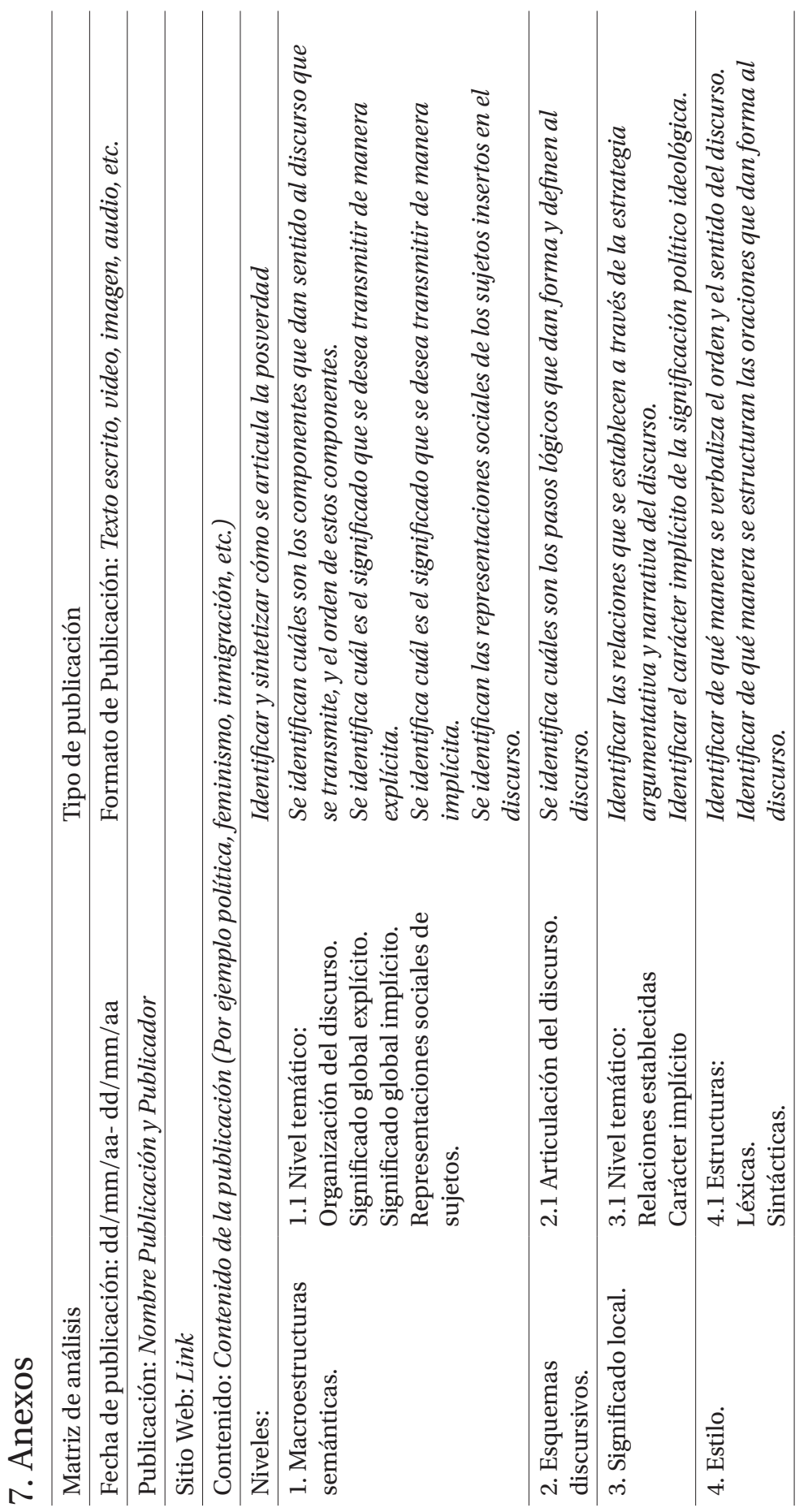




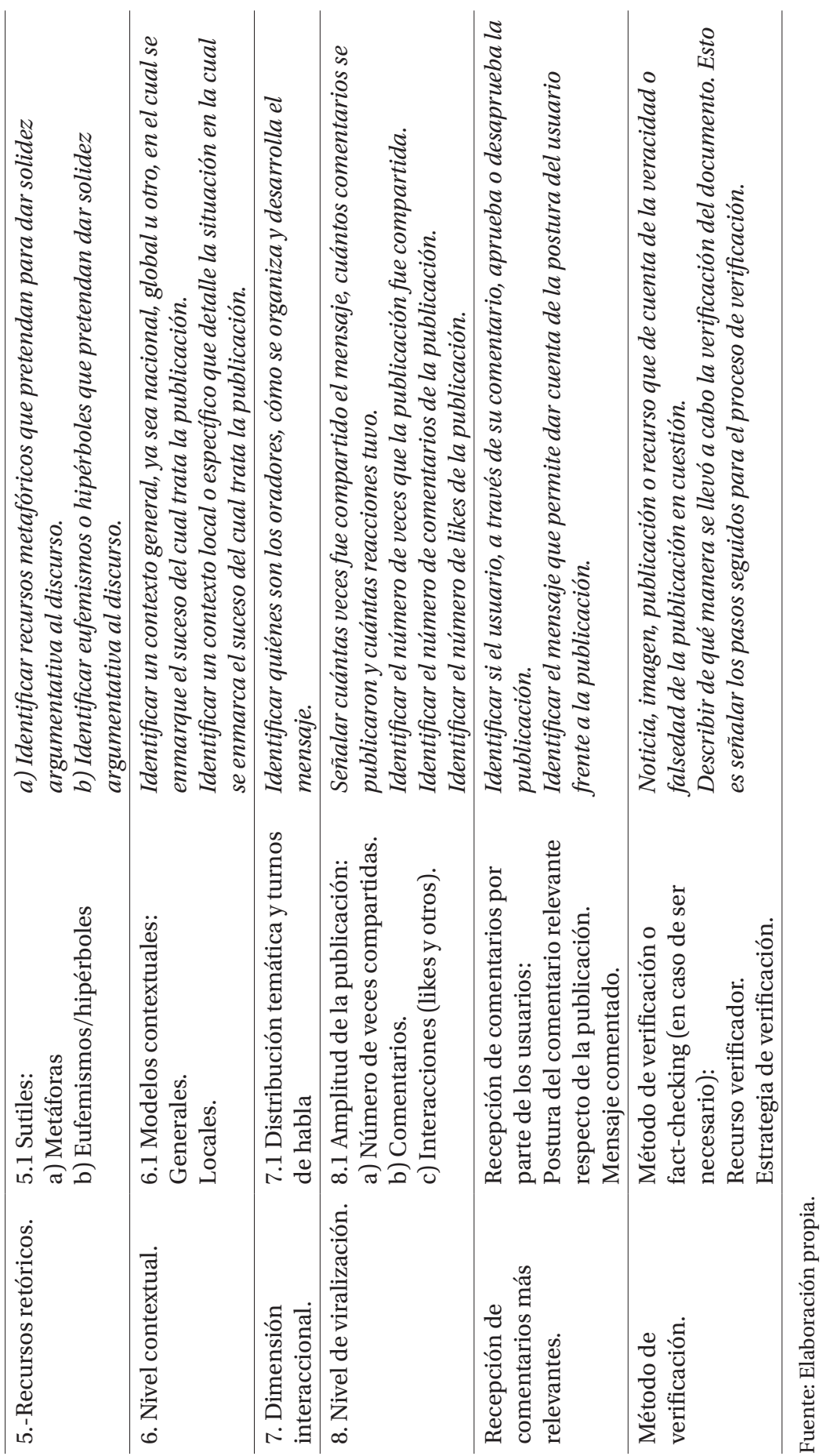

